\title{
Principles and Developments in Soil Grouting: A Historical Review
}

\author{
DIMITRIOS CHRISTODOULOU ${ }^{1}$, PHILOTHEOS LOKKAS ${ }^{2 *}$, IOANNIS MARKOU ${ }^{3}$, \\ ALEXANDROS DROUDAKIS $^{4}$, IOANNIS CHOULIARAS ${ }^{5}$, NIKOLAOS ALAMANIS $^{6}$ \\ ${ }^{1}$ Department of Environmental Sciences, University of Thessaly, Larissa, GREECE \\ ${ }^{2}$ Emeritus Professor, University of Thessaly, GREECE \\ ${ }^{3}$ Department of Civil Engineering, Democritus University of Thrace, Xanthi, GREECE \\ ${ }^{4} \mathrm{Ph} . D$. Civil Engineer, Geosynthetic Engineering Specialist, Technical Support Manager, Thrace \\ Nonwovens \& Geosynthetics, Xanthi, GREECE \\ ${ }^{5}$ Professor, General Department of Larissa, University of Thessaly, GREECE \\ ${ }^{6}$ Department of Agriculture - Agrotechnology, University of Thessaly, Larissa, GREECE
}

\begin{abstract}
Grouting includes a range of processes that involve the injection of wet or dry materials into the ground to provide improved engineering properties. Common aims are to increase strength or stiffness or to reduce permeability within the mass of ground treated. The simplest process in concept is the permeation of the pore spaces with a fluid grout which then sets, and provides the desired properties. Jet grouting employs erosion and mixing using high energy jets, to attack a wide-ranging set of soils and applications. This paper, mainly, addresses permeation grouting for the improvement of soils, in terms of strengthening or reduction of permeability, and compensation grouting for the displacement of structures during subsurface exploration. The historical evolution of these two grouting processes is described leading up to present-day practice. Reference is made to grouting materials, methods of injection, equipment, limitations and verification for each type of grouting. The grouts used to make permeation grouting are mainly suspensions and chemical solutions. The suspensions penetrate well into soils with granulometry up to coarse sand. On the contrary, the chemical solutions penetrate satisfactorily in finer formations up to fine sands or coarse sludges. Because some chemical solutions are toxic or generally harmful to the environment and humans, an effort has been made internationally in recent years to replace them with inorganic fine-grained suspensions.
\end{abstract}

Keywords: Permeation Grouting, Cement Suspensions, Microfine Cements, Sands, Injectability, Penetrability of Suspensions.

Received: May 25, 2021. Revised: October 9, 2021. Accepted: October 26, 2021. Published: November 29, 2021.

\section{Introduction}

The design related on the shear behavior of a soil material is of particular interest because it has a direct impact on practical problems of bearing capacity $[1,2]$, stability of slopes and embankments $[3,4,5]$ as well as permanent seismic movements of slopes $[6,7,8]$. The safe construction and operation of many technical projects often requires the improvement of the properties and mechanical behavior of the soil formations that appear in their area. Various methods are used to improve the soils, such as: the lowering of the well horizon, the vibrational condensation, the dynamic condensation, the preloading and the injections. The category of injections includes: (a) permeation grouting, (b) compensation grouting, (c) condensation injections and (d) high pressure vein injections. Permeation groutings are one of the oldest methods for improving soil formations and have a wide range of applications [9]. According to Sudheer Kumar et. al.
(2020), cement grouting technique is more efficient than compaction method [10].

The term "injection" means the passage, under pressure, of a fluid material to the required depth from the soil surface. The injection material, which is either a suspension of solid granules in water or a solution of chemicals, displaces the water from the soil pores and coagulates or solidifies in a relatively short period of time.

In general, permeation groutings aim at increasing the shear strength, the density and the stiffness, along with a reduction of the compressibility and the soil permeability. An appropriate injection program may: (a) be performed as part of the preliminary fieldwork prior to the commencement of project's construction, (b) be part of the construction of the main project, or (c) designed and executed ex post when unforeseen circumstances arise during the construction and/or operation of a project. 
The grouts used to perform permeation groutings, based on their composition, can be divided into: (a) Suspensions, (b) Solutions, (c) Emulsions and (d) Foams.

In the category of suspensions belong these of clay and bentonite, the mixtures of bentonite-cement, pozzolanic-cement, Portland cement and finegrained cements.

Typical representatives of chemical solutions are sodium silicate, aminoplastics, phenoplastics, acrylics and acrylamides.

The most popular emulsions are asphalt, a combination of asphalt - soap - casein in water, and asphalt with a suitable filler such as clay in water, which have been applied to soil stabilization and waterproofing problems.

Foams include cement or clay-cement suspensions that can undergo a physical or chemical modification that creates air bubbles within them.

Practically, and in terms of Engineering applications, the distinction has prevailed in the following types of grouts: (a) Cement grouts, (b) Fine cement grouts, (c) Fuel solutions and (d) Resins. Cement suspensions are low cost and environmentally friendly, but have a limited scope which reaches up to the coarse sands. On the contrary, chemical solutions can penetrate finegrained sands or coarse-grained sludges, but they are more expensive and some of them are considered harmful to the environment and humans. With the aim of replacing these chemical solutions with suspensions that are harmless to the environment, but also equally effective in terms of their penetration into soil formations, efforts have been made to develop new suspension-type materials based on fine-grained cements. The MC500 is the oldest fine-grained cement in the literature and appeared on the international market in the early 1980s. The volume of applications of fine-grained cements has been systematically increased over the last 20 years. Due to stricter environmental protection laws and lower costs against chemical solutions, fine-grained cements appear to be gradually replacing chemical solutions in the field of impregnation injections. Fine-grained cements have been used mainly to control groundwater flows and/or to improve soil strength, in applications including dams, tunnels, landfills, bridges and large construction projects.

\section{Injections in General}

The improvement of soil properties and mechanical behavior can be accomplished on site by performing an appropriate injection program. Injection is defined as the transmission process of a fluid material under pressure, to the required depth from the soil surface. The injection material, which is either a suspension of solid granules in water or a solution of chemicals, displaces the water from the soil pores and coagulates or solidifies in a short time. Injections are generally intended to either increase the shear strength, density and stiffness of the soil or to reduce compressibility and permeability.

\subsection{Injection Categories}

There are many criteria by which injection methods can be classified; they are related to the type of injection, the application cases, the 'grid' of the injection points and the sequence of the manufacturing steps. The categories of injections as defined by European standards EN12715: 2000 and EN12716: 2000 are as follows:

\subsubsection{Permeation Grouting}

The use of permeation grouting is a method of improving the properties and mechanical behavior of the soil. The method is generally expensive and its choice depends on the relative cost with respect to other alternative solutions. It is based on the replacement of water (or air) of soil voids or rock mass cracks by a grout, that is pressed under low pressure, so as not to disturb the soil formation. It is the oldest method of injection and is usually applied to relatively small areas of soil that are far from the soil surface. The method is used in technical projects, aiming at controlling underground flows, increasing the shear strength of soil formation, reducing deformation or subsidence and filling gaps [9].

\subsubsection{Compensation Grouting}

This type of grouting is divided into two subcategories: a) Compaction and b) Fracturing Grouting.

In Compaction grouting, a very thick and durable grout is injected into loose soils, forming grout "bulbs" that move and compact the adjacent soil, without penetrating the soil voids. The evolution of Compaction grouting began in the mid-1930s, but its systematic use began in the late 1960s. It is applied only to certain types of soils and is based on the creation of a "bulb", consisting of injection material, whose volume increases as new injection material is injected into the soil under high pressure. This material has a high viscosity and acts as a three-dimensional "jack", displacing the soil grains and resulting finally to its compaction. They are mainly used in technical landslide restoration 
projects and/or in order to strengthen the soil adjacent to tunnel excavations.

In Fracturing groutings, a high-density, lowviscosity grout is injected into the soil formation, causing it to fracture and eventually move from its original position. Due to the fracture they cause, they are also characterized as uncontrolled injections. Fracturing grouts are only used to repair subsidence.

\subsubsection{Jet Grouting}

Jet grouting is a soil treatment technique for stabilizing soft ground by mixing cement slurry with in-situ soil. Jet grouting has been widely used for soft ground modification in various underground projects to form base seals and buried grout struts for deep excavations, structural support around tunnel eyes at the entrance and departure sites of tunnel boring machine, as well as sealing of leaking joints in diaphragm walls [11]. High pressure jet injections have been used in Japan since about 1970. They first appeared in Europe in the 1980s and have recently begun to gain recognition as technically acceptable solutions in the United States and elsewhere. This is a technique that uses special drilling heads equipped with nozzles that spray water and injection material at high speed under high pressure. Water first corrodes the soil material and then mixes with injection material. Thus, a new material is created (mixture of soil and injection material) that has the desired properties. More specifically, the jet grouting involves the injection of cement slurry under high pressure from a nozzle fixed on a rotating monitor into the ground. The resulting high speed fluid jet erodes the in-situ soil and simultaneously mixes it with cement slurry to form a soil-cement column. Some applications have indicated that the shear strength of the soil-cement column could reach to several megapascal [11]. Jet grouting was initially patented in 1968, under the name Chemical Churning Pile (CCP) method, which is the fore runner of the single fluid system. With further improvement of the installation process and supporting equipment, alternate systems were developed, including the double fluid system, triple fluid system, multi-fluid method (SSS-MAN), Rodin Jet Pile (RJP) and Metro Jet System (MJS) (11). The appropriate procedure is as follows: a high-speed fluid (water jet or grout jet) is injected through small diameter nozzles into the subsoil to erode the surrounding soil, while the nozzles are rotated and lifted towards the ground surface at a constant speed. The eroded soil is simultaneously mixed with the injected grout to form the admixture, and a soil-cement column with a quasi-cylindrical shape would be formed after some days of solidification [11].

Based on the different methods of fluid injection, jet-grouting technology can be classified into three basic types: a) single fluid system (only grout), b) double fluid system (grout and air), or c) triple fluid system (water, grout, and air). The single fluid system utilizes grout as the cutting jet as well as to achieve cementation of the eroded soil. In the double-fluid system, a compressed air shroud is introduced around the grout jet to enhance the cutting distance of the grout jet. In the triple-fluid system, water is used for the cutting jet together with a compressed air shroud, and grout is injected separately through a lower nozzle at much smaller pressure to mix with the eroded soil. The adoption of a lower viscosity fluid such as water (in comparison with that of grout) allows the cutting distance to be further enhanced, especially in cohesive soils [11].

\subsection{Historical background on Permeation Grouting}

The first application of injections mentioned in the international literature is credited to the French engineer Charles Berigny, who in 1802 used grouts of clay and calcium oxides to stabilize stone walls in the port of Dieppe, which had lost their strength due to corrosion between the stones. Through this method, named by him "procédé d' injection", the stabilization and reduction of the permeability of the local alluvial deposits was achieved. Portland cement was first injected in England in 1838 by Marc Isambard Brunel to build the first Thames tunnel, and in France by Collin (1839) to fill cracks in the body of the Grosbois Dam [12, 13]. At the beginning of the $20^{\text {th }}$ century, due to the introduction of high-pressure pumps and pressure gauges, the ability to control the permeation pressure and the flow of grout increased considerably, resulting in a significant improvement on the equipment for performing an injection program [13]. The development of railway networks in the first half of the last century led to the widespread use of cement injections, especially for the repair and strengthening on the foundations of railway bridges to cope with the increased loads of trains. With James Greathead as a pioneer, between 1900 and 1930, mechanical systems and pumps were developed, capable of pumping high-pressure cement injection material deep into the ground. Through this way, problems related to the large dams that began to be built at that time and particularly problems of controlling the underground flows and strengthening the supports 
of the dams were solved [9]. Along with the development of the injection's technique with cement grouts, the first injection materials based on chemicals in solution form began to appear. The first application of injections using a chemical solution (concentrated sodium silicate) was attributed to Jeriorsky, who introduced a "twostage" injection method and for this reason he was awarded a patent in 1886 [12, 13]. In 1909 Lemaire and Dumont proposed a "one-step" chemical injection method with a dilute solution of silicon and acid, which, however, in application, presented significant practical problems. In 1925, the Dutchman Joosten perfected the "two-stage" method based on sodium hydrated silicate and extended its scope to soils with fine sand granulometry. The system introduced by Joosten was widely used in the construction of the Berlin Underground in the 1930s. An important impetus to the application of injections was given in 1933 by the invention of the "tube-à-manchette" (TAM) by the Swiss engineer Ischy, which allows the permeation of grouts with different properties, in any order at any step of time in the same drilling [12, 13]. In 1934 Mayer developed a "one-step" method by which he was able to control the curing time of the silicate suspension by helping to solve some of the practical problems of Joosten's method. Reports of cement grouts injections are also related to the construction of the Estacada Dam barrier wall in Oregon, USA (1910-1912). The construction of the Hoover Dam (1932-1936), however, was the first large-scale application of cement injections for stabilization and contributed decisively to the development of the existing knowledge for the time. A significant improvement in grout quality was provided by the colloidal mixer invented in 1934 by J.P. Morgan and was marketed in England in 1937 by Colcrete. The rapid mixing achieved, resulted in the removal of air from the grout, improved hydration and increased the amount of fine cement grains. This resulted in the possibility of making grouts with a lower water to cement ratio (W/C), with less exudation and higher strength. This type of mixer is still used today [12]. During World War II (1939-1945) there was, as expected, a slowdown of growth in the field of injections. After its end, however, a rapid progress was made, especially in the field of chemical solutions. Very important is the invention of an acrylic chemical solution (AM-9) by Mello, Hauser and Lambe in 1953, which presented a slightly higher viscosity than water, had the ability to penetrate muddy soils and provided excellent curing time $[13,15]$. In the early 1980 s, this solution was replaced by less toxic chemical solutions with
AC-400 as their main representative. Soletanche in 1957 developed a "hard" silicate solution using an organic ester capable of delivering sand resistances of 2-3 MPa [12]. From 1980 onwards, a shift was realized in technological development, towards a limitation on the use of chemical solutions, along with the development of new non-toxic materials, consisting of inorganic components that are less harmful to the natural environment $[13,16]$. In this context, the effort to explore and develop new finegrained cements, which were and are still widely used in injections, was included.

\subsection{Grouts for Permeation Injections}

In the literature there are several sources, in which the grouts are classified into categories based on different criteria (purpose of use, practical application, etc.). However, the most popular categorization of grouts is based on their rheology and cost [17]. According to EN 12715: 2000, they are distinguished as follows:

\subsubsection{Suspensions}

They are mixtures of water and solids with a grain size greater than $0.1 \mu \mathrm{m}$. They are the most economical solution compared to the grouts mentioned in the other categories and can be used to reduce permeability and increase the strength of soil formations. The viscosity of the suspensions increases dramatically during curing and takes a few hours up to a few days to obtain satisfactory strength. They generally exhibit Bingham-type rheological behavior. Grouts of this type are the suspensions of clay and bentonite, the mixtures of bentonite-cement, pozzolans-cement, pure Portland cement and fine-grained cements.

\subsubsection{Solutions}

They result from the dissolution of suitable chemical compounds in water and depending on the type of chemical compound used to prepare them, they are divided into: True Solutions and Colloidal Solutions. The actual solutions contain solids which present a size of molecules that mechanically cannot be separated from water. They show a very low viscosity that remains constant up to the hardening of grout, which occurs extremely abruptly (from a few seconds to an hour). Resins belong to this category. The resins have a viscosity ranging from 2 to $10 \mathrm{cP}$, behave like Newtonian fluids and generally undergo significant shrinkage, which leads to a reduced strength. There are several types of resins. Some of them, like phenoplastics, aminoplastics, polymers (foam materials) and polymethyl acrylates (PMAs) are still used, while 
acrylamides and lignosulfonates have not been recently used in applications due to their toxicity [13].

Colloids are characterized by granules of solids that are larger in size than molecules but smaller than the solids in grouts $(0.001 \mu \mathrm{m}<\mathrm{d}<0.1 \mu \mathrm{m})$. Their viscosity varies according to the admixtures used. At the beginning, the viscosity is low and gradually increases during the hardening, which, can last from several minutes up to a few hours. The modern composition of silicate solutions mainly requires the dissolution of sodium silicate in water with an inorganic (sodium aluminate) or organic (esters) hardener. A typical silicate solution with a composition of $50-60 \%$ sodium silicate, $8-10 \%$ hardener and $30-42 \%$ water has a viscosity between 10 and $200 \mathrm{cP}$ and behaves like a Newtonian fluid. The strength of these solutions depends on the silicon content (higher content increases the strength) and the type of hardener. In general, these grouts do not have high strengths and for this reason are used only to reduce the permeability of soil formations.

Some researchers also place fine-grained cement grouts in this category [13], while there are several sources that refer to solutions similar to the rheological behavior of fine-grained cement with high water to cement $\mathrm{W} / \mathrm{C}$ ratios during the first hours after their preparation. $[18,19]$.

\subsubsection{Mortars}

These are very dense grouts that consist of components similar to those of grouts, have a high angle of internal friction and are most commonly used for compaction or cavity filling injections.

\section{Suspension - Type Grout Components}

As mentioned in the previous paragraph, suspension-type grouts can even be soil-water mixtures. These grouts are the most economical solution, but at the same time they show many important disadvantages such as the inability to develop strength along with the difficulty of penetration. The most popular suspension - type grouts are those based on cement, whose main components are the common Portland cement and water. Depending on the needs of each application (high initial strength, resistance to chemical environment) it is possible to use different types of cement (aluminum, slag, etc.) instead of common cement. In addition, it is possible to add to the grouts some solids (sand, clay) with the main purpose of reducing the cost of injections, while the use of admixtures such as fly ash, slag silica fume and addition of chemical improvers (i.e. water reducers, superplasticizers, coagulation accelerators etc.) aims to improve some properties. The following sections list all the ingredients used in the manufacture of cement grouts and additionally indicate how they act on the properties of grouts.

\subsection{Water}

The quality of the water, used to make the cement grouts, should be controlled from the beginning because it is an important parameter of their composition. Generally, drinking water is considered suitable for the preparation of cement grouts [12, 20]. According to Van der Stoel [13], the $\mathrm{pH}$ value is the regulatory factor on the basis of which the choice should be made. This is based on the fact that the acidity of the water affects the setting time of the grouts. He argues, in fact, that when $\mathrm{pH}$ values range from 6 to 8 , the effect of acidity is considered negligible. Also, water, which contains sulfates (> $0.1 \%$ ), chlorine (> $0.5 \%$ ), sugars, suspended solids especially organic, or presents a high alkali content, is dangerous, especially for applications with high strength requirements in the presence of steel. Weaver (1991) [21], finally, proposes the use without testing whether the water is pure, i.e. without a salty, saltish or bitter taste).

\subsection{Cement}

Cement is a mortar, which, when mixed with water, can thicken and harden both in air and in water. It is mainly an excellent hydraulic mortar, which combines high hydraulicity and strength. Common Portland cements are mainly used for permeation grouting. The raw materials, which are necessary for the preparation of the main phases of Portland cements, are those that contain the oxides of calcium $(\mathrm{CaO})$, silicon $\left(\mathrm{SiO}_{2}\right)$, aluminum $\left(\mathrm{Al}_{2} \mathrm{O}_{3}\right)$ and iron $\left(\mathrm{Fe}_{2} \mathrm{O}_{3}\right)$. Limestone gives $\mathrm{CaO}$, while clay gives $\mathrm{SiO}_{2}, \mathrm{Al}_{2} \mathrm{O}_{3}$ and $\mathrm{Fe}_{2} \mathrm{O}_{3}$. Marls contain all four oxides in varying amounts depending on their composition. Furthermore, silica sand contains $\mathrm{SiO}_{2}$ and bauxite $\mathrm{Al}_{2} \mathrm{O}_{3}$. The main phases of Portland type cements are the following [22]:

- $\mathrm{C}_{3} \mathrm{~S}$ silica

- Calcium silicate $\mathrm{C}_{2} \mathrm{~S}$

- $\mathrm{C}_{3} \mathrm{~A}$ alumina

- Aluminum-iron calcium $\mathrm{C}_{2}(\mathrm{~A}, \mathrm{~F})$

The above phases are not present in the cements completely pure, but with small admixtures of $\mathrm{MgO}$, $\mathrm{TiO}_{2}, \mathrm{~K}_{2} \mathrm{O}, \mathrm{Na}_{2} \mathrm{O}, \mathrm{Mn}_{2} \mathrm{O}_{3}$ etc. Portland cement 
consists of clinker and gypsum (or gypsum and anhydride), which are collected in a very fine powder with a special surface of Blaine 2200-6000 $\mathrm{cm}^{2} / \mathrm{gr}$. The amount of gypsum that grinds together with the clinker depends on the fineness and type of cement and is necessary to regulate the setting. However, for reasons of volume stability, the amount of cement must be limited. Clinker is a product of firing (shells or extruders) of blast furnaces and the materials from which it is made are usually limestone and clay or marls that contain both materials. To improve the proportions of the firing mixture, silica sand and iron oxides can be added [22]. Cements have standard mechanical, chemical and physical properties, which are determined by performing standard tests. According to the European Standard EN 197-1: 2000, these properties are: strength after 2, 7 and 28 days, the initial setting time and the swelling after setting. Important properties of Portland cements are also Blaine fineness, density and loose weight. The most important property for choosing the right cement for injections is its fineness, which is expressed by the special Blaine surface (in $\mathrm{cm}^{2} / \mathrm{gr}$ and $\mathrm{m}^{2} / \mathrm{gr}$ ). The finer the cement is ground, the larger the surface to react with water and therefore the reaction (hydration) takes less time. The cement grains react with the water on their surface and this reaction proceeds gradually towards the center, until the grain is completely hydrated. If the fineness is low, the cement grains are not fully hydrated, while in cements with very high fineness we have the appearance of cracks in the hardened cement paste. The German Regulations define only a lower limit (minimum limit) for fineness at $2200 \mathrm{~cm}^{2} / \mathrm{gr}$ [22]. In general, in common Portland cements the fineness ranges from 350 to $800 \mathrm{~m}^{2} / \mathrm{gr}$ [17]. However, the fineness is not enough to ensure the optimal choice of cement, but should be combined with the knowledge of its granulometric curve. Most common cements have a maximum grain diameter ranging from 50 to $200 \mu \mathrm{m}$, thus limiting the scope of application of cement injections in coarse-grained soils with $D_{10} \geq 1 \mathrm{~mm}$ and $\mathrm{k} \geq 5 \cdot 10^{-2} \mathrm{~cm} / \mathrm{sec}$ and in rocks presenting cracks of thickness $\alpha \geq 160 \mu \mathrm{m}$ [23]. Due to these limitations, arose the need for the production of new fine-grained cements that would be the basis for the preparation of grouts with improved properties, able to penetrate into finer formations. In the following paragraphs, issues related to the aforementioned materials are developed in detail.

\subsection{Additives}

The term additives refers to natural or artificial materials that are added to cement grouts to improve certain properties and/or reduce their manufacturing costs. In the international literature they appear under various terms and mainly with the term "fillers" and are divided into non-active materials that are inert (sands, clays) and pozzolans and chemical property improvers that are active ingredients [24].

\subsubsection{Sands}

It is added to pure cement suspensions for the purpose of making economical grouts, especially in cases where a high solids content, a low water content and a relatively high shear strength are required.

Sands with a grain size between 5 and $0.075 \mathrm{~mm}$ are preferred, but in cases where the permeation length or distance is greater than 300 meters the maximum grain size should be reduced to $0.5 \mathrm{~mm}$ while the ratio of sand to cement should not be higher than $3: 1$, so that the grains of sand remain in suspension and do not precipitate [24].

In general, in cases where large gaps are required to be filled, a sand-to-cement ratio of up to 10:1 is suggested [17].

\subsubsection{Clays}

The small grain size, the ability to absorb water, but also to form dense structures even in small contents, led to the use of clays in cement suspensions as it reduces exudation [24]. Different types of clays can be used (natural clay, kaolin, illite, etc.), but the most common clay in the field of injections is bentonite, which has a water absorption capacity of more than $500 \%$ (5 times its weight) [25].

The use of bentonite improves the resistance to exudation under pressure, increases stability and penetration, but also increases viscosity and cohesion [26], significantly reduces the rate of resistance [24] and the final strength of grout [27].

Bentonite is added to the cement suspensions in prehydrated form (suspension in water) and always before the introduction of other ingredients into the mixture. Otherwise, the grout presents strong cracks while the ability to stabilize the suspension is dramatically reduced [26].

There are several types of bentonite, but in the field of permeation injections, montmorillonite silicate is considered to be the most effective choice $[17,27]$.

\subsubsection{Pozzolans}

Pozzolans are silicate and aluminosilicate materials, which usually do not exhibit cementing properties 
on their own, but have the potential - in the presence of free calcium in the cement - to take part in the hydration process [24]. They are distinguished in natural and artificial pozzolans, the most important of which are the following:

\section{Slag}

It is an artificial pozzolan, which is a non-metallic by-product of iron ore processing. The main type of slag used in the preparation of suspension type grouts is the blast furnace slag and participates as a cement substitute in grouts in up to $45 \%$ [26]. It takes an active part in the hydration process of the cement and can react with other additives to make ettringite. However, in the absence of other ingredients it hydrates very slowly and for this reason it should always be used in combination with cement. This reduced slag hydration capacity is ideal for increasing the initial setting time and, therefore, slag is used to control the setting time of fine-grained cements. In addition, it is added to cement grouts to react with calcium hydroxide in order to reduce the porosity of the suspension mass and improve the resistance to chemicals [26].

\section{Fly ash (FA)}

It is a low-cost artificial pozzolan, which comes from the cleaning of the flue gases in the chimneys of the coal combustion plants for the production of electricity. There are two types of ash (C and F), which differ in their chemical composition depending on the type of coal used for combustion. The use of ash in cement grouts slightly reduces exudation, improves resistance to exudation under pressure and permanence [27] and slows down the hydration process and the rate of resistance development [26]. In fine-grained cement grouts it presents the same effect as slag, but leads to grouts of lower resistance to unobstructed compression. It has to be noted that the participation of type $\mathrm{C}$ fly ash in the grouts at a rate of more than $15 \%$ by weight of cement, leads to their rapid deterioration [26].

In addition to many environmental benefits, fly ash utilization provides end-products with superior engineering and physical qualities as well as economic benefits, considering the utilization potential in construction-related applications such as cement production and concrete products in the form of highway pavement concrete, structural concrete, and roller compacted concrete, bricks, blocks and paving stones; artificial lightweight aggregate, structural fills or embankments, stabilization of waste materials, mineral filler in asphalt paving, flowable/structural fill and grouting mixes. The fly ash, being a cementitious coal combustion by-product, promises high volume utilization in grouting applications by addition of other mineral admixtures when necessary. The fly ash grouts provide required engineering performance in improving ground stability by increasing strength and shearing resistance as well as reducing the permeability of soils treated with enhanced technical, rheological, durability and economic advantages over sand and cement grouts. The fly ash grout is also cost-effective when alternative suspension, emulsion or solution materials are considered. Fly ash grout composite formed of various combinations of high-volume fly ash, cement, lime and high range water reducing chemical admixture has been investigated to define short-term engineering performance in terms of physicochemical (chemical compound analysis, unit weight, void ratio, specific gravity, linear shrinkage, hydraulic conductivity) and mechanical properties (unconfined compressive strength and flexural strength), excluding durability as the long-term engineering performance. The overall short-term engineering performance indicates high volume fly ash utilization potential in grouting applications.

\section{Silica fume (SF)}

This type is a by-product of the production of silicon or silicon-containing alloys with a content of at least $75 \%$. The proper disposal of silica fume, as an industrial waste, is one of the major issues for environmentalists since leaving it directly in the environment may cause severe health problems. On the other hand, the amorphous structure, high $\mathrm{SiO}_{2}$ content, and large specific surface area make the silica fume reactive to the alkali product of cement to produce the additional amounts of calciumsilicate-hydrate $(\mathrm{CSH})$ phase, enhancing the bonding of solid phase and improving the strength of cement-silica fume binary system considerably. Silica fume is a fine-grained powder (grain size $<1 \mu \mathrm{m}$ ) and is used in cement grouts to improve the penetration and permanence and also to reduce the permeability of the grout [26]. Furthermore, through the use of silica fume it is possible to improve the stability, the resistance to exudation under pressure, but also the strength of the grout by reducing the porosity of its mass. The use of silica fume as a substitute for cement is proposed in a content of up to $10 \%$ by weight of dry cement [27]. Furthermore, the particles of silica fume are 100 to 150 times smaller than the cement grains and because silica fume particles have near-perfect spheres, they can occupy the micro voids in the matrix and provide a much denser structure, which in turn may decrease 
the permeability of the system and therefore increase its resistance to the aggressive environment $[29,30]$. Apart from pozzolanic activity and filling effect of silica fume, this material may affect the hydration kinetics $[31,32]$ this is because silica fume particles may prepare more nucleation sites, a process that accelerates the hydration reactions of cement and contributes towards a decrease of the setting times [33]. Therefore, silica fume, as an additive, can partially be replaced with cement, which could result in promoting the performance of the cement, contributing to waste recycling of silica fume, and also reducing the production demand for cement, thus mitigating carbon emissions since it has been reported that the production of one ton of cement, on average, generates 0.7 to 1 tons of carbon dioxide [34].

\section{Natural pozzolan}

It is found in nature in various rock formations or can arise from clays and shales. Known types of natural pozzolan are Theraic earth and Trasi, for which their successful use in cement grouts has been reported [26]. In particular, they react with calcium hydroxide to produce secondary ettringite, thus yielding grouts with improved durability. In addition, the use of these materials slows down the rate of their strength and reduces the heat released by hydration reactions. The latter effect is considered desirable in cases where large amounts of grout are required [26].

\subsubsection{Chemical Property Improvers}

The term "chemical property improvers" refers to chemicals that are added in small quantities to cement injections to improve their specific properties. In the international literature these materials appear in various terms, but in recent years the terms "admixtures" (EN 934-2: 2001) or "chemical admixtures" (ASTM C 494-04) have prevailed. The main types of chemical property improvers are:

\section{Liquidators or Plasticizers}

They are the main and most widespread category of chemical improving properties of concrete and grout. In the international literature but also in scientific standards (EN 934-2: 2001, ASTM C 49404) it is possible to be found with the term "water reducers". The liquidators improve the rheological properties of the grouts causing a reduction in their viscosity and coherence, thus enabling the preparation of grouts with lower ratios of water to cement (W/C) under the same rheological characteristics. It is typically reported that a cement grout with a W/C ratio of 1:1 containing a liquidator has comparable rheological properties to a cement grout without a liquidator and a W/C ratio of $3: 1$ or 4:1 [25].

Materials with even greater potential to affect the rheological properties of cement grouts are the Superplasticizers (SP) or High Range Water Reducers (HRWR).

Van der Waals forces, that are attractive along with electrostatic forces that are attractive or repulsive, are exerted between the cement grains suspended in the water. Of these forces, only electrostatics can be neutralized and this is influenced by liquidators [28]. The drastic ingredients of the liquidators adhere to the surface of the granules and either alter the electrical charge of the granules by making the electrostatic forces purely repulsive (naphthalene sulfonate and formaldehyde sulfonate melamine products) or separate the granules, creating chains of various polymers.

Many commercially available liquidators possibly exhibit combined effects in cement grouts. Thus, according to their properties the liquidators can accelerate coagulation or hardening, or, vice-versa, decelerate coagulation, as it happens in the case of superfluidizers (EN 934-2: 2001, ASTM C 494-04). More information on the use and action of fluidizers and superfluidizers is provided by Eklund (2005) [28].

\section{Accelerators}

These are mainly inorganic salts that are used to increase the rate of resistance for the suspension, speeding up the hydration process. These materials are divided into two main categories: coagulation accelerators and curing accelerators.

In practice, most materials of this type cause both effects (e.g. calcium chloride) and for this reason it is not easy to include a product in one of the two categories. Sodium silicate (water glass), calcium chloride, sodium aluminate are mentioned as typical coagulation accelerators, and potassium carbonate and sodium carbonate are mentioned as typical curing accelerators [25]. The dose of the accelerator must be calculated accurately, as an incorrect use can cause side effects such as slowing of coagulation or excessive hydration. Also, the choice of the appropriate accelerator should be based on the type of cement used. For example, calcium chloride is reported to act as a retarder on slag-based grout and aluminum cements. In many cases, accelerators can affect the permanence of the suspension, while chloride-containing accelerators cause corrosion of the steel in the reinforced concrete [28]. 


\section{Retarders}

Retarders have the opposite effect on grout behavior compared to accelerators. In particular, they cause an increase in the time required to start the hydration process. Typical retarders are sugars, citric acid and lignosulfonates. In general, the use of injectors is not very widespread [25].

\section{Flow regulators or viscosity enhancers}

These are chemicals that have the ability to regulate the flow properties of grouts and adapt them to the requirements of the projects. They are distinguished in the high molecular weight materials, that create grouts with "short duration" flow (gel grouts that remain insoluble in water), and in the low molecular weight materials, that create grouts with "long duration" flow (grouts in a liquid state for a satisfactory period of time). In general, flow regulators form grouts with shear thinning behavior. Grouts with this type of rheological behavior, flow when under pressure and harden sharply when at rest. In this way, the grout shows increased resistance to exudation under pressure, which can be improved up to 10 times [26]. There are several types of viscosity improvers (polyacrylic polymers, polyvinyl alcohol, etc.), but the most common and effective type is welan gum. It is a high molecular weight biopolymer which is typically added to cement suspensions with a content of $0.1 \%-0.2 \%$ by weight of cement [26].

\section{Fine-grained Cements}

Common cement-based suspensions -as defined by the various standards (ASTM C 150-04, EN 197-1: 2000 , etc.)- are capable of penetrating coarsegrained soil materials effectively (e.g. gravel and coarse-grained sands) with a permeability of $10^{-1}$ $\mathrm{cm} / \mathrm{sec}$ and above [35]. Various types of chemical solutions are used to reinforce lower permeability soils (up to $10^{-4} \mathrm{~cm} / \mathrm{sec}$ ) that can penetrate into soil formations such as fine sands and sludges. However, it has been shown that materials of this type have significant disadvantages, such as high cost, unsatisfactory durability, low strength and can also cause environmental pollution due to their toxicity $[15,35,36,37]$. In the last thirty years, new materials have been developed, which are presented as a counter-proposal to the use of chemical solutions for the above problems. These are extremely fine-grained cements whose suspensions have the ability to penetrate and reinforce even finegrained sands [18, 38, 39, 40, 41, 42, 43, 44]. The main advantage of these materials over chemical solutions is that they are composed entirely of minerals and thus do not cause adverse environmental effects.

\subsection{Definition}

For the reinforcement of soils, characterized as medium or fine-grained sands, various types of solutions have been developed in the last thirty years that are able to penetrate effectively into soil formations with a permeability coefficient of up to $10^{-4} \mathrm{~cm} / \mathrm{sec}$. These solutions, which are mainly chemical, have significant disadvantages associated with high cost, unsatisfactory durability and environmental impact due to their toxic behavior $[14,35,36]$. On the other hand, mortars developed on the basis of common cements can penetrate effectively into coarse-grained soils (e.g. gravelly and coarse-grained sands) with a permeability of $10^{-}$ $1 \mathrm{~cm} / \mathrm{sec}$ [35]. Therefore, in order to achieve satisfactory penetration with the least possible impact on the natural environment, the use of finegrained cements for the preparation of suspensions that are capable to permeate fine-grained formations has been proposed in recent years $[9,18,38]$.

\subsection{Categorization of Fine-Grained Cements}

The categorization of cements into "fine-grained" along with their clear separation is based on the establishment of certain criteria and standards that are applied. The Norwegian standard separates the fine-grained cements into: microfine with $d_{95}<30$ $\mu \mathrm{m}$ and ultrafine with $\mathrm{d}_{95}<15 \mu \mathrm{m}$ [25]. In the USA, according to the ACI Committee 552, fine-grained cements are those that show a maximum grain size, $\mathrm{d}_{\max }=15 \mu \mathrm{m}$ [45], while the European standard EN 12715: 2000, defines as fine-grained (microfine cements) those with $\mathrm{d}_{95}<20 \mu \mathrm{m}$ and Blaine fineness $>8000 \mathrm{~cm}^{2} / \mathrm{gr}$. Finally, in Britain, ultrafine cements are defined those having a maximum diameter of grain $\mathrm{d}_{\max }<6 \mu \mathrm{m}$ [12].

\subsection{Methods of Preparation}

The preparation of suspensions from fine-grained cements is carried out by two methods: the dry and the wet grinding process [46]. Most fine-grained cements are produced by the dry method and are products of grinding Portland common cement, blast furnace slag or some pozzolan. Grinding takes place in special mills, in which the size of the maximum grain is reduced [26]. The second method of making fine-grained cements, referred to in the literature as the wet method, grinds the cement in mills in the presence of water, on site.

Efforts in this direction have led to the production of suspensions called Microsol [35] and Cemill [47], although there are other standard methods of 
preparing suspensions, such as Ahrens (1997) [48] and Huang et al. (2002) [46]. However, Cemill suspensions appear to have a very short workability and require a complex manufacturing process, while Ahrens suspensions do not exhibit satisfactory rheological properties and result from extremely slow process [26]. Naudts and Landry in 2003 [49] introduced the PASREM grinding machine which enables the preparation of suspensions in a short period of time along with satisfactory rheological properties. In general, the wet method allows the production of the desired amount of suspension by reducing waste, favors more accurate project budgets and requires much lower costs compared to the preparation of fine-grained cements with the dry method. However, it does not allow the production of materials with a maximum grain size of less than $18 \mu \mathrm{m}[49]$.

\subsection{Fine-grained Cements as Commercial Products}

A significant number of commercially available fine-grained cements has been developed in recent years. Specific information on the production method and composition of these fine-grained cements is not available from the producers. Table 1 below gives the trade names of some fine-grained cements and their characteristics, based on the existing information from the international literature. The MC-500 is the oldest fine-grained cement in the international literature and is produced by the Japanese cement company Onoda Cement. Following the absorption of the company by Taiheiyo Materials, this product is available in the market of Southeast Asia and Australia under the brand name Alofix MC, while in the USA under the name MC-500. It is a mixture of finely ground Portland cement and slag in a ratio of 4:1 [50], which consists only of minerals and has a specific gravity of $3.0 \pm 0.1 \mathrm{gr} / \mathrm{cm}^{3}$. Its manufacturers recommend its combined use with the NS-200 hyperplasticizer at a dose of $2 \%$ by weight of dry cement. From Figure 1 it yields that MC-500 / Alofix MC based cement suspensions can achieve penetration comparable to that of chemical solutions. SuperFine and SuperFine-L are finegrained, slag cements manufactured by the Japanese company Nittetsu. They have an average grain size of $3 \mu \mathrm{m}$ and a specific gravity of $3.0 \mathrm{gr} / \mathrm{cm}^{3}$ and $2.92 \mathrm{gr} / \mathrm{cm}^{3}$, respectively [21]. The use of Nittetsu SuperFine has been reported by several researchers $[51,52,53]$. Clarke introduced later the MC-500 to the U.S.A. under the trade name M5 and then manufactured M1 and M3 cements [54, 55, 56], giving them the trade names MC-100 and MC-300 respectively. MC-100 is a fine-grained slag, while MC-300 is a fine-grained Portland cement [57, 58, 59].

Table 1. Trade names and characteristics of fine-grained cements

\begin{tabular}{|c|c|c|c|c|}
\hline $\begin{array}{l}\text { Commercial } \\
\text { Designation }\end{array}$ & Manufacturer & $\begin{array}{l}\text { Country of } \\
\text { origin }\end{array}$ & $\begin{array}{l}\text { Fineness by } \\
\text { Blaine } \mathbf{~ m}^{2} / \mathbf{k g r}\end{array}$ & $\begin{array}{l}\text { Feature Size } \\
\text { Granules } \mu \mathrm{m}\end{array}$ \\
\hline$*$ MC-500 / Alofix MC & Taiheiyo Materials & Japan & $>800$ & $\mathrm{~d}_{\max }=15$ \\
\hline$\$ \mathrm{MC}-300$ & \multirow{2}{*}{$\begin{array}{l}\text { DeNeef } \\
\text { (Taiheiyo Materials) }\end{array}$} & \multirow{2}{*}{ U.S.A. } & $>1300$ & $\mathrm{~d}_{\max }<40$ \\
\hline \# MC-100 & & & $>1200$ & $\mathrm{~d}_{\max }=8$ \\
\hline$\$$ Microblend A & \multirow{2}{*}{$\begin{array}{l}\text { Microblend } \\
\text { Solutions Inc. }\end{array}$} & \multirow{2}{*}{ Canada } & $>1200$ & $\mathrm{~d}_{\max }<20$ \\
\hline Microblend AF & & & $>1200$ & $\mathrm{~d}_{\max }<20$ \\
\hline * Spinor A6 & \multirow{3}{*}{$\begin{array}{l}\text { Ciment d' Origny } \\
\text { (Holcim Group) }\end{array}$} & \multirow{3}{*}{ France } & & $\mathrm{d}_{98}=6$ \\
\hline * Spinor A12 & & & $>1000$ & $\mathrm{~d}_{98}=12$ \\
\hline${ }^{*}$ Spinor A16 & & & 1200 & $\mathrm{~d}_{98}=16$ \\
\hline MC 20 RS & Holcim Brazil & Brazil & & $\mathrm{d}_{98}=20$ \\
\hline *Fine Hard & Mitsubishi Materials & Japan & 1260 & $\mathrm{~d}_{\max }=12$ \\
\hline Micromix & & & 1200 & $\mathrm{~d}_{\max }=10$ \\
\hline \# Mikrodur R-F & \multirow{4}{*}{ Dyckerhoff AG } & \multirow{4}{*}{ Germany } & 1200 & $\mathrm{~d}_{95}=16$ \\
\hline \# Mikrodur R-U & & & 1600 & $\mathrm{~d}_{95}=9.5$ \\
\hline \# Mikrodur R-X & & & 1900 & $\mathrm{~d}_{95}=6$ \\
\hline${ }^{\$}$ Mikrodur P-F & & & 1200 & $\mathrm{~d}_{95}=16$ \\
\hline
\end{tabular}




\begin{tabular}{|c|c|c|c|c|}
\hline${ }^{\$}$ Mikrodur P-U & & & 1600 & $\mathrm{~d}_{95}=9.5$ \\
\hline \$ Microcem A & \multirow{2}{*}{$\begin{array}{l}\text { Addiment } \\
(\text { Sika AG) }\end{array}$} & \multirow{2}{*}{ Germany } & 1400 & $\mathrm{~d}_{95}=9$ \\
\hline${ }^{\$}$ Microcem B & & & 1500 & $\mathrm{~d}_{98}=8$ \\
\hline Type V Premium & \multirow{2}{*}{ U.S Grout } & \multirow{2}{*}{ U.S.A. } & 1710 & $d_{90}<5$ \\
\hline Type V Standard & & & 1510 & $\mathrm{~d}_{90}<8$ \\
\hline${ }^{*}$ Superfine & \multirow{2}{*}{ Nittetsu Cement Co. } & \multirow{2}{*}{ Japan } & $>900$ & $\mathrm{~d}_{\max }=10$ \\
\hline * Superfine-L & & & $>900$ & $\mathrm{~d}_{\max }=10$ \\
\hline Micro A & \multirow{3}{*}{$\begin{array}{l}\text { Ube Industries Ltd. } \\
\text { Cement Division }\end{array}$} & \multirow{3}{*}{ Japan } & 1010 & $\mathrm{~d}_{98}=20$ \\
\hline Micro N & & & 990 & $\mathrm{~d}_{98}=20$ \\
\hline Micro S & & & 1020 & $\mathrm{~d}_{98}=20$ \\
\hline \$ Rheocem 650 & \multirow{3}{*}{$\begin{array}{l}\text { BASF Construction } \\
\text { Chemicals }\end{array}$} & \multirow{3}{*}{ Switzerland } & $>625$ & $\mathrm{~d}_{95}<15$ \\
\hline${ }^{\$}$ Rheocem 800 & & & $>800$ & $\mathrm{~d}_{98}<15$ \\
\hline${ }^{\$}$ Rheocem 900 & & & $>900$ & $\mathrm{~d}_{98}<10$ \\
\hline$\$$ Ultrafin 12 & \multirow{2}{*}{$\begin{array}{l}\text { Cementa } \mathrm{AB} \\
\text { (HeidelbergCement) }\end{array}$} & \multirow{2}{*}{ Sweden } & $2200(\mathrm{BET})$ & $\mathrm{d}_{95}=12$ \\
\hline${ }^{\$}$ Ultrafin 16 & & & $>800$ & $\mathrm{~d}_{95}=16$ \\
\hline Micro Matrix & Halliburton & U.S.A. & $>900$ & $\mathrm{~d}_{98}=15$ \\
\hline
\end{tabular}

Cement based on: \$Portland, $\quad$ " slag, * Portland + slag

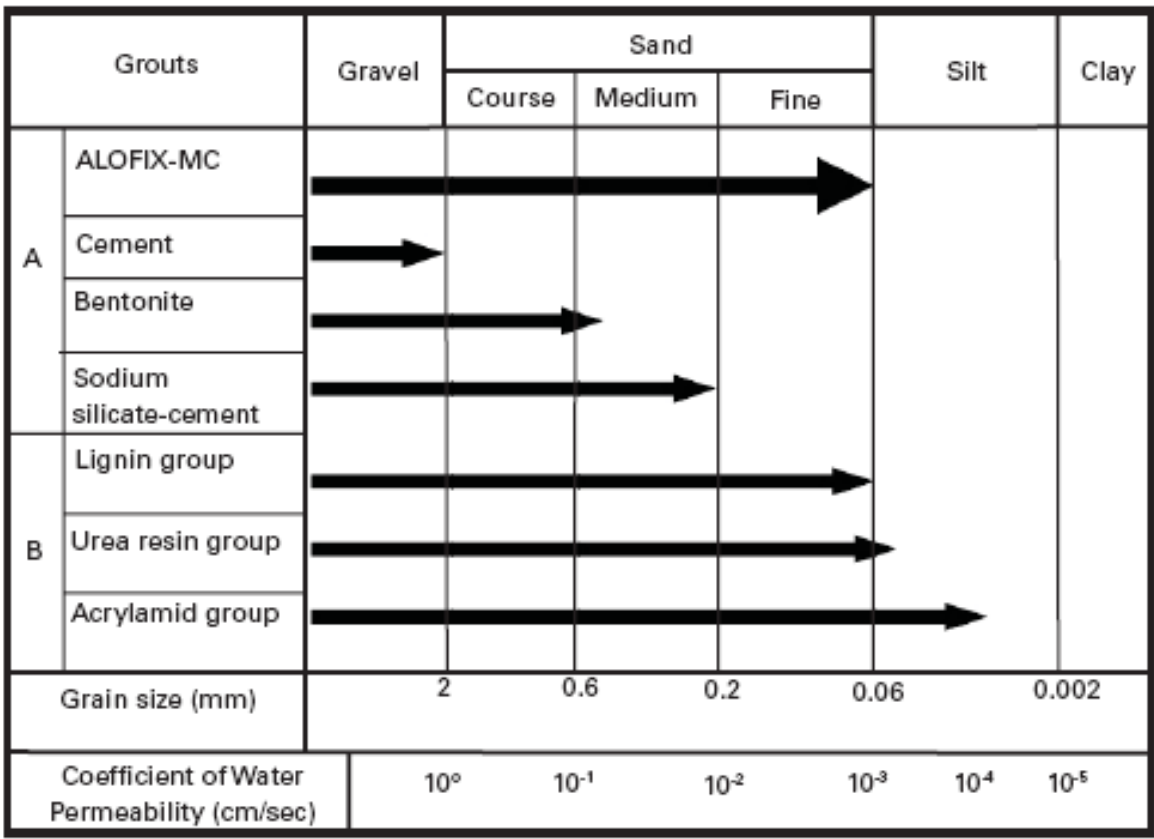

Fig. 1: Comparison of the penetration of MC-500 / Alofix MC cement suspensions with other grouts [60]

The U.S. Company Grout prepares cement-based injection materials by both dry and wet methods. The fine-grained cements Type V Premium and Type V Standard have a specific weight of 2.63 $\mathrm{gr} / \mathrm{cm}^{3}$ and $2.70 \mathrm{gr} / \mathrm{cm}^{3}$ and an average grain size of $2.50 \mu \mathrm{m}$ and $4.0 \mu \mathrm{m}$, respectively. Their chemical composition includes 55\% Thera earth and 45\% super grounded type IV Portland cement. In the dry state, their combined use with a hyperplasticizer in doses of $1.5 \%$ and $2.5 \%$ by weight respectively of dry cement is required. The specific materials are the basis for the production of suspensions with a ratio $\mathrm{W} / \mathrm{C}$ of $0.6: 1$ and $0.8: 1$, respectively, following the wet method and a very specific process in terms of the manner and time of mixing and stirring. The use of Type V Premium cement is noted in their research efforts by Henn et al., (2001) [51] and Henn et al., (2005) [52]. Important references in the 
international literature are related to the Spinor cements (A6, A12 and A16) of the French company Soletanche-Bachy [16, 61]. Their main representative is the fine-grained cement $\mathrm{A} 12$, which is slag having a specific weight of 2.94 $\mathrm{gr} / \mathrm{cm}^{3}$. The manufacturer proposes the use of a superplasticizer in a dosage of $3 \%$ by weight of dry cement along with W/C ratios from $1: 1$ to $3: 1$. Spinor A12 can also be used for the preparation of Microsol grouts, which are prepared by the wet method. It is also reported that MC $20 \mathrm{RC}$ fine cement is manufactured in Brazil by Holcim Brazil [62].

A significant part of the international market is occupied by fine-grained cements under the brand name Mikrodur, which are sold by Dyckerhoff AG. These are products consisting of either pure Portland (with the mark P) or pure slag (with the mark R). Finosol products are also available from the same company, which are suspensions resulting from the mixing of blast furnace slag, clinker, coagulation and admixtures controller in field applications.

Characteristic of these suspensions is the individual preparation of their ingredients before the final mixing. Depending on their fineness, Mikrodur and Finosol materials are divided into $\mathrm{F}$ (Fine), $\mathrm{U}$ (Ultrafine) and X (EXtrafine). Mikrodur and Finosol cements have been used in various research efforts $[35,63,64,65]$. Products of the company BASF Construction Chemicals are the fine-grained cements under the brand name Rheocem, which are based on pure Portland cement. Depending on their fineness, they are divided into products 650,800 and 900 [66]. The manufacturer recommends their use in combination with the plasticizer Rheobuild $2000 \mathrm{PF}$ in a dosage ranging from $1.0 \%$ to $3.0 \%$ by weight of dry cement. Henn et al. (2001) [51], used in field applications, suspensions based on the finegrained Microcem A and Microcem B cements of
Addiment company. These are fine-grained pure Portland cements that have a specific weight of 3.20 $\mathrm{gr} / \mathrm{cm}^{3}$. The Swedish company Cementa AB is also active in the production of fine-grained cements, introducing on the market the fine-grained cements Ultrafin 12 and Ultrafin 16 with a specific weight of $3.10-3.20 \mathrm{gr} / \mathrm{cm}^{3}$. The Norwegian company Elkem ASA Materials proposes the product Ultrafin 12 as a basis for the preparation of fine-grained suspensions available in the market under the brand name MultiGrout System. The Cemill designation identifies the wet method by which cement suspensions are prepared on site using Portland conventional cement as a base. The method was proposed by De Paoli et al. (1992b) [47] and aims at developing an on-site production process of finegrained material using common cement. This process made it possible to produce not only unstable grouts (Cemill-I), but also fixed grouts using bentonite (Cemill-S). These objectives were achieved with a special device, which has two functions: (a) achieves very strong dispersion of cement granules without the addition of a corresponding anticoagulant and (b) implements a progressive procedure of elaborating the coarse cement fraction until it reaches the desired levels of fineness without the need for this coarse material to be removed [47]. Regarding the chemical composition of fine-grained cements, it is emphasized that, mainly, they consist of the same oxides as Portland cements, but in different proportions. Another element, which promotes the use of fine-grained cements for permeation injections, is the fact that they are composed of inorganic and non-toxic materials, an element that is particularly beneficial in preventing environmental pollution. Table 2 below gives typical chemical compositions of commercially available finegrained cements, while Table 3 lists characteristic cases of use for fine-grained cement grouts.

Table 2. Typical chemical compositions of fine-grained cements

\begin{tabular}{lllllll}
\hline $\begin{array}{l}\text { Chemical } \\
\text { Ingredient }\end{array}$ & $\begin{array}{l}\mathbf{S i O}_{2} \\
(\boldsymbol{\%})\end{array}$ & $\begin{array}{l}\mathrm{Al}_{2} \mathbf{O}_{3} \\
(\boldsymbol{\%})\end{array}$ & $\begin{array}{l}\mathbf{F e}_{2} \mathbf{O}_{3} \\
(\%)\end{array}$ & $\begin{array}{l}\mathbf{C a O} \\
(\boldsymbol{\%})\end{array}$ & $\begin{array}{l}\mathbf{M g O} \\
(\boldsymbol{\%})\end{array}$ & $\begin{array}{l}\mathbf{S O}_{3} \\
(\%)\end{array}$ \\
\hline MC-100 & 35.4 & 16.0 & 0.3 & 43.3 & 3.5 & 0.3 \\
MC-300 & 17.9 & 4.9 & 3.5 & 61.6 & 2.6 & 2.4 \\
MC-500 & 29.0 & 13.2 & 1.2 & 49.2 & 5.6 & 1.2 \\
Fine Hard & 31.6 & 13.6 & 0.7 & 46.4 & 6.1 & 1.6 \\
Micro A & 28.8 & 11.3 & 1.0 & 48.9 & 5.4 & 1.4 \\
Micro N & 30.9 & 12.9 & 0.5 & 44.3 & 6.3 & 1.6 \\
Micro S & 26.9 & 10.4 & 1.4 & 51.1 & 4.6 & 2.0 \\
Spinor A12 & 31.0 & 9.5 & 1.3 & 44.0 & 6.5 & \\
MC 20 RS & 24.3 & 7.7 & 2.0 & 52.7 & 3.8 & 3.7 \\
\hline
\end{tabular}




\begin{tabular}{lllllll}
\hline Micro Matrix & 20.4 & 6.4 & 2.7 & 62.3 & 1.0 & 3.3 \\
\hline
\end{tabular}

Table 3. Typical cases of use for fine-grained cement grouts

\begin{tabular}{|c|c|c|c|c|}
\hline Reference & Cement & Work & $\begin{array}{l}\text { Soil } \\
\text { Formation } \\
\end{array}$ & Target \\
\hline \multirow{3}{*}{$\begin{array}{l}\text { Shimoda and } \\
\text { Ohmori, } 1982\end{array}$} & MC-500 & Railway tunnel & Loose volcanic gravel & ${ }^{*} \mathrm{C},{ }^{\#} \mathrm{~S}$ \\
\hline & $\mathrm{MC}-500$ & Tunnel & Fine sand & $\mathrm{S}$ \\
\hline & $\mathrm{MC}-500$ & Dam & Branched granite & $\mathrm{S}$ \\
\hline Moller et al., 1983 & $\mathrm{MC}-500$ & Tunnel & Branched granite & $\mathrm{C}$ \\
\hline Clarke, 1984 & $\mathrm{MC}-500$ & Tunnel & Branched granite & $\mathrm{C}$ \\
\hline Dasika, 1985 & $\mathrm{MC}-500$ & Building & Sand & $\mathrm{S}$ \\
\hline Winter et al., 1986 & MC-500 & Building & $\begin{array}{l}\text { Medium - fine sand } \\
\text { with fines }(6-18 \%)\end{array}$ & $\mathrm{S}$ \\
\hline Legendre et al., 1987 & Microsol & Oil well & Thin sand layer & $\mathrm{C}$ \\
\hline Brand et al., 1988 & $\mathrm{MC}-500$ & Landfill & Fine sand & $\mathrm{C}, \mathrm{S}$ \\
\hline Weaver et al., 1992 & $\mathrm{MC}-500$ & Landfill & Branched dolomite & $\mathrm{C}$ \\
\hline Clarke et al., 1992 & MC-100+MC-300 & Dam & Branched rock mass & $\mathrm{C}$ \\
\hline Ballivy et al., 1997 & Spinor A12 & Tunnel & Gneiss and limestone & $\mathrm{S}$ \\
\hline Clarke et al., 1997 & $\begin{array}{l}\text { MC-100+MC-300 } \\
\text { MC-500 }\end{array}$ & Dam & Branched rock mass & $\mathrm{C}$ \\
\hline Van der Stoel, 1999 & Microcem & $\begin{array}{l}\text { Tunnels } \\
\text { subway }\end{array}$ & Sand layers & $S$ \\
\hline \multirow{3}{*}{$\begin{array}{l}\text { Tolpannen and } \\
\text { Syrjanen, } 2003\end{array}$} & Ultrafin 12 & Coal storage & Rock mass & $\mathrm{C}, \mathrm{S}$ \\
\hline & Rheocem 900 & Gas storage & Rock mass & $\mathrm{C}, \mathrm{S}$ \\
\hline & Rheocem 650 & Athletic Center & Rock mass & $\mathrm{C}$ \\
\hline Pallardy et al., 2003 & Spinor A12 & Road tunnel & Rock mass & $\mathrm{C}$ \\
\hline Abreu et al., 2005 & MC $20 \mathrm{RS}$ & Bridge & Soil & $\mathrm{S}$ \\
\hline $\begin{array}{l}\text { Hognestad and } \\
\text { Frogner, } 2006\end{array}$ & Rheocem 800 & Railway tunnel & $\begin{array}{l}\text { Hard rock mass } \\
\text { (limestone) }\end{array}$ & $\mathrm{C}$ \\
\hline
\end{tabular}

*C: Groundwater control, \#S: improved strength of soil formation

\section{Conclusions}

1) From the above review, it has been emerged that geotechnical engineering both in research and design but mainly in its application and construction has played and still plays an extremely important role for the infrastructure not only in Greece, but all over the world.

2) This paper reviews constituent materials, properties and applications of grouts for soil grouting and especially permeation grouting. The effectiveness of grouting process requires proper skills, understanding, meticulous attention and intuitive perception.

3) The improvement of properties and the mechanical behavior of soil formations can be achieved on the spot by performing an appropriate injection program. The injection program may: (a) be performed as a part of the preliminary field work prior to the commencement of a project's construction, (b) be a part of the construction of the main project, or (c) be designed and executed as a "treatment" when unforeseen circumstances arise during the construction of a project.

4) Injections are generally intended either to increase the shear strength, density and stiffness of the soil or to reduce compressibility and permeability.

5) The grouts used to make permeation injections are mainly suspensions and chemical solutions.

6) The suspensions penetrate satisfactorily in soils with granulometry up to coarse sand.

7) Chemical solutions penetrate satisfactorily in more fine-grained formations up to fine-grained sands or coarse-grained sludges.

8) Because some chemical solutions are toxic or generally harmful to the environment and humans, an effort has been made internationally in recent years to replace them with inorganic fine-grained cement-based suspensions. 
9) Finally, the interesting applications of the above science in the field of soil improvement increase both the knowledge of students along with their theoretical background and enhance their training.

\section{References:}

[1] Philotheos Lokkas, Emmanouil Papadimitriou, Nikolaos Alamanis, Grigorios Papageorgiou, Dimitrios Christodoulou, and Theodoros Chrisanidis, "Significant Foundation Techniques for Education: A Critical Analysis", WSEAS Transactions on Advances in Engineering Education, doi: 10.37394/232010.2021.18.2., E-ISSN: 22243410, Vol. 18, 2021, pp. 7-26.

[2] Philotheos Lokkas, Ioannis Chouliaras, Theodoros Chrisanidis, Dimitrios Christodoulou, Emmanouil Papadimitriou, Evangelos Paschalis, "Historical background and evolution of Soil Mechanics", WSEAS Transactions on Advances in Engineering Education, DOI: 10.37394/232010.2021.18.10, E-ISSN: 2224-3410, Vol. 18, 2021, pp. 96-113.

[3] Nikolaos Alamanis, "Failure of Slopes and Embankments under Static and Seismic Loading", American Scientific Research Journal for Engineering, Technology and Sciences (ASRJETS), Vol. 35, No.1, 2017, pp. 95-126.

[4] Papageorgiou G.P., Alamanis N. and Xafoulis N., "Acceptable movements of road embankments", Electronic Journal of Structural Engineering, 20(1), 2020, pp 30-32, Melbourne, Australia.

[5] Alamanis Nikolaos, Zografos Christos, Papageorgiou Grigorios, Xafoulis Nikolaos and Chouliaras Ioannis, "Risk of retaining systems for deep excavations in urban road infrastructure with respect to work staff perception", International Journal of Scientific \& Technology Research, Vol. 9, Issue 2, 2020, pp. 4168-4175, ISSN 2277-8616.

[6] Dimos Zachos, Georgios Bakalis, Konstantinos Bakalis, Nikolaos Alamanis, Grigorios Papageorgiou, Nikolaos Xafoulis, "A methodology for selecting the required cross- $^{-}$section of a self- supporting retaining bulkhead, on a vertical excavation front, of an energy conduit passage trench", Energy Systems, Springer https://doi.org/10.1007/s12667-021-00429-9.

Received: 3 Jan. 2021 / Accepted: 20 February
2021 / Published on line: 06 March 2021, (C) Springer-Verlag GmbH Germany.

[7] Alamanis N., Dakoulas P., "Simulation of random soil properties by the Local Average Subdivision method and engineering applications", Energy Systems, Springer. https://doi.org/10.1007/s12667-019-00362-y.

Print ISSN 1868-3967, Online ISSN1868-3975 p.p 1-21. Received: 6 March 2019 / Accepted: 2 October 2019, Published on line: 07 November 2019, (C) Springer-Verlag GmbH Germany.

[8] Alamanis N., Dakoulas P., "Effect of spatial variability of soil properties on permanent seismic displacements of slopes with uniform load", 14th Baltic Sea Geotechnical Conference, 18-19 Jan 2021, Helsinki, Finland.

[9] Atmatzidis D.K., "Soil improvements with injections", University Notes, University of Patras, 1990.

[10] Sudheer Kumar G., Sumanth M.K. and Madimi S., "A review paper on stabilization of sandy soil by using cement grouting technique", Journal of Critical Reviews, Vol 7, Issue 14, 2020, ISSN- 2394-5125, pp. 902-908.

[11] Wang Z.F., Shen S.L., Ho C.E. and Kim Y.H., "Jet Grouting Practice: An Overview", Geotechnical Engineering Journal of the SEAGS \& AGSSEA, Vol. 44, No. 4, 2013, ISSN 0046-5828.

[12] Littlejohn S., "The development of practice in permeation and compensation grouting: A historical review (1802-2002): Part 1 Permeation Grouting", Proceedings of the $3^{\text {rd }}$ International Conference on Grouting and Ground Treatment, Johnsen F.L., Bruce A.D. and Byle J.M., Editors, New Orleans, La., U.S.A., ASCE, New York, U.S.A., Geotechnical Special Publication No. 120, Vol. 1, 2003, pp. 50-97.

[13] Van der Stoel A.E.C., "Grouting for pile foundation improvement", Ph.D. Thesis, Technische Universiteit Delft, Published and Distributed by: DUP Science, 2001.

[14] Karol R.H., "Grout penetrability", Proceedings, Issues in Dam Grouting, Baker W.H., Editor, Denver, Colorado, U.S.A., ASCE, New York, U.S.A., 1985, pp. 27-33.

[15] Karol R.H., "Chemical grouts and their properties", Proceedings, Conference on Grouting in Geotechnical Engineering, Baker W.H., Editor, New Orleans, Louisiana, U.S.A., ASCE, New York, U.S.A., Vol. 1, 1982, pp. 359-377.

[16] Saada Z., Canou J., Dormieux L., Dupla J.C. and Maghous S., "Modelling of cement 
suspension flow in granular porous media", International Journal for Numerical and Analytical Methods in Geomechanics, Vol. 27, Issue 7, 2005, pp 691-711.

[17]Bruce A.D., Littlejohn S. and Naudts C.A., "Grouting materials for ground treatment: A practitioner's guide", Proceedings, Conference on Grouting: Compaction, Remediation, Testing, Vipulanandan C., Editor, Logan, Utah, U.S.A., ASCE, New York, U.S.A., Geotechnical Special Publication No. 66, 1997, pp. 306-334.

[18] Arenzana L., Krizek R.J. and Pepper S.F., "Injection of dilute microfine cement suspensions into fine sands", Proceedings of the International Conference on Soil Mechanics and Foundation Engineering, A.A. Balkema, Rotterdam, The Netherlands, Vol. 2, 1989, pp. 1331-1334.

[19]Bouchelaghem F. and Almosni A., "Experimental determination of the longitudinal dispersivity during the injection of a microcement grout in a one-dimensional soil column", Transport in Porous Media, Vol. 52, No 1, 2003, pp 67-94.

[20]Eriksson M. and Stille H., "A method for measuring and evaluating the permeability of grouts", Proceedings of the $3^{\text {rd }}$ International Conference on Grouting and Ground Treatment, Johnsen F.L., Bruce A.D. and Byle J.M., Editors, New Orleans, U.S.A., ASCE, New York, U.S.A., Geotechnical Special Publication No. 120, Vol. 2, 2003, pp. 13261337.

[21] Weaver K.D., "Dam Foundation Grouting", ASCE, New York, U.S.A., 1991.

[22] Sideris K., "Technology of building materials", Volume 1, University Notes, Department of Civil Engineering, Democritus University of Thrace, 1998.

[23] Markou I.N., "Grinded Greek lignite fly ash as a suspension-type injection material for on-site soil improvement - reinforcement", $\mathrm{PhD}$ Thesis, Department of Civil Engineering, University of Patras, Greece, 1995.

[24]Littlejohn G.S., "Design of cement-based grouts", Proceedings, Conference on Grouting in Geotechnical Engineering, Baker W.H., Editor, New Orleans, Louisiana, U.S.A., ASCE, New York, U.S.A., Vol. 1, 1982, pp. 35-48.

[25] Tolpannen P. and Syrjanen P., "Hard rock tunnel grouting practice in Finland, Sweden, and Norway: Literature study", Technical Report, Finnish Tunnelling Association, 2003.
[26] Naudts A., Landry E., Hooey S. and Naudts W., "Additives and admixtures in cement-based grouts", Proceedings of the 3rd International Conference on Grouting and Ground Treatment, Johnsen F.L., Bruce A.D. and Byle J.M., Editors, New Orleans, La., U.S.A., ASCE, New York, U.S.A., Geotechnical Special Publication No. 120, Vol. 2, 2003, pp. 11801191.

[27] Chuaqui M. and Bruce D.A., "Mix design and quality control procedures for high mobility cement-based grouts", Proceedings of the 3rd International Conference on Grouting and Ground Treatment, Johnsen F.L., Bruce A.D. and Byle J.M., Editors, New Orleans, La., U.S.A., ASCE, New York, U.S.A., Geotechnical Special Publication No. 120, Vol. 2, 2003, pp.1153-1168.

[28]Eklund D., "Penetrability due to filtration tendency of cement-based grouts", Doctoral Thesis, Division of Soil and Rock Mechanics, Royal Institute of Technology, Stockholm, Sweden, 2005.

[29] Asavapisit S., Nanthamontry W. and Polprasert C., "Influence of condensed silica fume on the properties of cement-based solidified wastes", Cem. Concr. Res., 31 (2001), pp. 1147-1152

[30] Koksal F., Gencel O. and Kaya M., "Combined effect of silica fume and expanded vermiculite on properties of lightweight mortars at ambient and elevated temperatures", Constr. Build. Mater., 88, 2015, pp. 175-187.

[31]Benaicha M., Roguiez X., Jalbaud O., Burtschell Y. and Alaoui A.H., "Influence of silica fume and viscosity modifying agent on the mechanical and rheological behavior of self compacting concrete", Constr. Build. Mater., 84, 2015, pp. 103-110.

[32]Liu J., Li Y., Ouyang P. and Yang Y., "Hydration of the silica fume-Portland cement binary system at lower temperature", Constr. Build. Mater., 93, 2015, pp. 919-925.

[33] Muller A.C.A., Scrivener K.L., Skibsted J., Gajewicz A.M. and McDonald P.J, "Influence of silica fume on the microstructure of cement pastes: new insights from 1H NMR relaxometry", Cem. Concr. Res., 74, 2015, pp. 116-125.

[34] Tsai C.H., Huang R., Lin W.T. and Wang H.N., "Mechanical and cementitious characteristics of ground granulated blast furnace slag and basic oxygen furnace slag blended mortar", Mater. Des., 60 (2014), pp. 267-273.

[35]Legendre Y., Hery Ph. and Vattement H., "Microsol grouting, A method for grouting fine 
alluvium", Proceedings, 6th International Conference Offshore Mechanics and Arctic Engineering Symposium, Houston, Texas, U.S.A., ASCE, New York, U.S.A., Vol. 1, 1987, pp. 433-440.

[36] Shimoda M. and Ohmori H., "Ultrafine grouting material", Proceedings, Conference on Grouting in Geotechnical Engineering, Baker W.H., Editor, New Orleans, Louisiana, U.S.A., ASCE, New York, U.S.A., Vol. 1, 1982, pp. 77-91.

[37]Dupla J.-C., Canou J. and Gouvenot D., “An advanced experimental set-up for studying a monodirectional grout injection process", Ground Improvement, Thomas Telford Ltd, Vol. 8, No. 3, 2004, pp. 91-99.

[38]Clarke W.J., (1984), "Performance characteristics of microfine cement", ASCE Preprint 84-023, Atlanta, Ga., U.S.A., pp. 1-14.

[39] Dano C. and Hicher P.Y. and Tailliez S., "Engineering properties of grouted sands", Journal of Geotechnical and Geoenvironmental Engineering, ASCE, New York, U.S.A., 2004, pp. 328-338.

[40]Christodoulou D.N., Droudakis A.I., Pantazopoulos I.A., Markou I.N. and Atmatzidis D.K., "Groutability and Effectiveness of Microfine Cement Grouts", Proceedings, 17th International Conference on Soil Mechanics and Geotechnical Engineering: The Academia and Practice of Geotechnical Engineering, Alexandria, Egypt, Hamza et al. (Editors), IOS Press, Vol. 3, 2009, pp. 22322235.

[41] Pantazopoulos I.A., Markou I.N., Christodoulou D.N., Droudakis A.I., Atmatzidis D.K., Antiohos S.K., Chaniotakis E., "Development of microfine cement grouts by pulverizing ordinary cements", Cement and Concrete Composites, 34(5), 2012, 593-603.

[42] Markou I.N., Christodoulou D.N., Petala E.S., Atmatzidis D.K., "Injectability of Microfine Cement Grouts into Limestone Sands with Different Gradations: Experimental Investigation and Prediction", Geotechnical and Geological Engineering Journal, Vol. 36, Issue 2, 2018, pp. 959-981.

[43] Markou I.N., Christodoulou D.N., Papadopoulos B.K., "Penetrability of microfine cement grouts: experimental investigation and fuzzy regression modeling", Canadian Geotechnical Journal, 52(7), 2015, pp. 868882.

[44] Mollamahmutoglu M., "Treatment of medium to coarse grained sands by fine grained Portland cement (FGPC) as an alternative grouting material to silicate-ester grouts", Cement, Concrete and Aggregates, 25(1), 2003, pp. 1-6.

[45] Perret S., Palardy D. and Ballivy G., "Rheological behavior and setting time of microfine cement-based grouts", ACI Materials Journal, Vol. 97, No. 4, 2000, pp. 472-478.

[46] Huang Z., Chen M. and Chen X., "A developed technology for wet-ground fine cement slurry with its applications", Cement and Concrete Research, Elsevier Science Ltd, Vol. 33, 2002, pp. 729-732.

[47] De Paoli B., Bosco B., Granata R. and Bruce D.A., "Fundamental observations on cement based grouts (2): Microfine cements and the Cemill process", Proceedings, Conference on Grouting, Soil Improvement and Geosynthetics, Borden R.H., Holtz R.D. and Juran I., Editors, New Orleans, Louisiana, U.S.A., ASCE, New York, U.S.A., Geotechnical Publication No. 30, Vol. 1, 1992b, pp. 486-499.

[48] Ahrens H.E., "A new and superior ultrafine cementitious grout", Proceedings, Conference on Grouting: Compaction, Remediation, Testing, Vipulanandan C., Editor, Logan, Utah, U.S.A., ASCE, New York, U.S.A., Geotechnical Special Publication No. 66, 1997, pp.188-196.

[49] Naudts A. and Landry E., "New on-site wet milling technology for the preparation of ultrafine cement-based grouts", Proceedings of the 3rd International Conference on Grouting and Ground Treatment, Johnsen F.L., Bruce A.D. and Byle J.M., Editors, New Orleans, La., U.S.A., ASCE, New York, U.S.A., Geotechnical Special Publication No. 120, Vol. 2, 2003, pp. 1200-1207.

[50]Bruce D.A., "Trends and developments in American grouting practice", Proceedings, Conference on Grouting in the Ground, Bell A.L., Editor, London, England, Thomas Telford, London, England, 1992, pp. 573-589.

[51] Henn R., Ganse P., Bandimere S., Smoak G. and Warner J., "Comparison of penetration test results of grouts made with various ultrafine cement products", Proceedings of the Rapid Excavation and Tunneling Conference, Elsevier Science B.V., Amsterdam, 2001, pp. 345-361.

[52] Henn R. and Davenport R., "Ultrafine cement: A critical component of a grouting program", Tunnels and Tunnelling International, 2005, pp. 27-29.

[53] Brachman R.W.I., Martin C.D., and Gilliss S.A., "Grout field trials in outwash sands", 
Canadian Geotechnical Journal, Vol. 41, No. 1, 2004, pp. 1-11.

[54]Clarke W.J., Boyd M.D. and Helal M., "Ultrafine cement tests and dam test grouting", Proceedings, Conference on Grouting, Soil Improvement and Geosynthetics, Borden R.H., Holtz R.D. and Juran I., Editors, New Orleans, Louisiana, U.S.A., ASCE, New York, U.S.A., Geotechnical Publication No. 30, Vol. 1, 1992, pp. 626-638.

[55]Clarke W.J., Boyd M.D. and Helal M., "Ultrafine cement tests and drilling Warm Spring Dam", Proceedings, Geotechnical Practice in Dam Rehabilitation, Specialty Conference, Anderson L.R., Editor, Raleigh, North Carolina, U.S.A., ASCE, New York, U.S.A., Geotechnical Publication No. 35, 1993, pp. 718-732.

[56]Clarke W.J. and McNally A.C., "Ultrafine cement for oilwell cementing", Rocky Mountain Regional Meeting/Low Permeability Reservoirs Symposium and Exhibition, Denver, CO, U.S.A., Society of Petroleum Engineers (SPE), Richardson, TX, United States, 1993, pp. 291298.

[57] Weaver K., Coad R.M. and McIntosh K.R., "Grouting against hazwaste", Civil Engineering, ASCE, New York, U.S.A., Vol. 62, No. 5, 1992a, pp. 70-72.

[58] Helal M. and Krizek R.J., "Preferred orientation of pore structure in cement-grouted sand", Proceedings, Conference on Grouting, Soil Improvement and Geosynthetics, Borden R.H., Holtz R.D. and Juran I., Editors, New Orleans, Louisiana, U.S.A., ASCE, New York, U.S.A., Geotechnical Publication No. 30, Vol. 1, 1992, pp. 526-540.

[59] Schwarz L.G. and Krizek R.J., "Effects of mixing on rheological properties of microfine cement grout", Proceedings, Conference on Grouting, Soil Improvement and Geosynthetics, Borden R.H., Holtz R.D. and Juran I., Editors, New Orleans, Louisiana, U.S.A., ASCE, New York, U.S.A., Geotechnical Publication No. 30, Vol. 1, 1992, pp. 512-525.

[60] www.parchem.com.au

[61]Bouchelaghem F. and Vulliet L., "Mathematical and numerical filtrationadvection-dispersion model of miscible grout propagation in saturated porous media", International Journal for Numerical and Analytical Methods in Geomechanics, John Wiley \& Sons, Ltd., Vol. 25, 2001, pp. 11951227.
[62] Abreu J.V., Mezzalira F.A. and Cruz L.O.M., "Brazilian special cements for shotcrete and injections in underground constructions", Proceedings, Conference on Waterproofing, ITA-AITES, Sao Paulo, Brazil, 2005.

[63] Hakansson U., Hassler L. and Stille H., "Rheological properties of microfine cement grouts with additives", Proceedings, Conference on Grouting, Soil Improvement and Geosynthetics, Borden R.H., Holtz R.D. and Juran I., Editors, New Orleans, Louisiana, U.S.A., ASCE, New York, U.S.A., Geotechnical Publication No. 30, Vol. 1, 1992, pp. 551-563.

[64] Reinhardt H.W., "Ultra-fine cements for special applications", Advanced Cement Based Materials, Vol. 1, 1993, pp. 106-107.

[65] Mittag J. and Savvidis S., "The groutability of sands - results from one-dimensional and spherical tests", Proceedings, $3^{\text {rd }}$ International Conference on Grouting and Ground Treatment, Johnsen F.L., Bruce A.D. and Byle J.M., Editors, New Orleans, La., U.S.A., ASCE, New York, U.S.A., Geotechnical Special Publication No. 120, Vol. 2, 2003, pp. 13721382.

[66] Mollamahmutoglu M., Yilmaz Y., Kutlu I., "Grouting performance of microfine cement and silica fume mix into sands", Journal of ASTM International, Vol. 4, Issue 4, 2007.

Contribution of Individual Authors to the Creation of a Scientific Article (Ghostwriting Policy)

D. Christodoulou had the idea of writing this article. In fact, together with $\mathrm{Ph}$. Lokkas, organized the research along with the methodology of the paper and actively participated in literature review.

Ph. Lokkas organized the research along with the methodology of the paper and participated in both the translation and the submission of the text.

I. Markou had the original idea of dealing with this subject and succeeded in financing the research. He actively participated in literature review.

A. Droudakis contributed to the writing of literature review.

I. Chouliaras and N. Alamanis presented previous experimental and analytical studies.

Sources of Funding for Research Presented in a Scientific Article or Scientific Article Itself

The research effort reported herein is part of the research project (PENED) which is co-financed by E.U. European Social Fund (80\%) and the Greek Ministry of Development - GSRT (20\%).

\section{Creative Commons Attribution License 4.0}

(Attribution 4.0 International, CC BY 4.0)

This article is published under the terms of the Creative Commons Attribution License 4.0

https://creativecommons.org/licenses/by/4.0/deed.en_US 